Japanese Psychological Research

1980 , Vol. 22, No. 1, 32-41

\title{
ATTRIBUTION OF PERSONAL RESPONSIBILITY AND DISSONANGE REDUCTION
}

\author{
HARUKI SAKAI AND KIYOSHI ANDOW ${ }^{1}$
}

University of Tokyo

\begin{abstract}
The relationship between personal responsibility and dissonance reduction was investigated in a situation where an individual had to undergo a negative consequence caused by an agent beyond his control, i.e., by chance. Eighty participants received either strong or weak electric shock, depending on the oddness or evenness of spots of a die thrown either by the experimenter (Experimenter-Caused condition) or by the participant himself (ParticipantCaused condition). It was found that participants in the Participant-Caused condition evaluated electric shocks less painful, estimated their heart rates to be less faster, and perceived the experimenter more intelligent and favorable than participants in the Experimenter-Caused condition. These results were interpreted as lending support to the newly reformulated dissonance theory.
\end{abstract}

Cognitive dissonance theory has been reformulated by some authors since the original statement (Festinger, 1957) appeared in the late 1950s. Brehm and Cohen (1962) stated that dissonance was aroused only when an individual was bound by a behavioral commitment to one of the inconsistent cognitions. Aronson (1968) stressed that the self concept or some other firmly held expectancy must be involved for dissonance to be aroused (e.g., Nel, Helmreich, \& Aronson, 1969). Recently Wicklund and Brehm (1976) have refined the earlier revisions in terms of the concept of personal responsibility: ... dissonance arousal requires the perceptions of a strong causal link between oneself and the potentially dissonancearousing event. Unless such a connection is perceived, the behavior and consequence are two irrelevant cognitions as far as the person is concerned, and the terms consonance and dissonance are not applicable (p. 70). ... Dissonance reduc-

I The authors wish to express their thanks to Associate Professor Toshiro Suenaga for his helpful comments on the earlier manuscript. Requests for reprints should be sent to Haruki Sakai, Department of Psychology, University of Tokyo, Bunkyoku, Tokyo, 113 Japan. tion may be observed only to the degree that the individual sees himself as responsible for bringing cognitions into an inconsistent relationship (p. 10).

These reformulations cited above clearly concerned with the necessary conditions for dissonance arousal, and it may be said, as Greenwald and Ronis (1978) pointed out, that dissonance theory has evolved along a direction of convergence with ideas from the tradition of self theory.

Thus far several studies have investigated the relationship between personal responsibility and dissonance reduction. For example, Sogin and Pallak (1976) offered subjects high or low choice for their performing a dull random-numberwriting task. Half of the subjects were told that task usefulness depended on the subject and that task results from others had been useful, while the other half were told that task usefulness depended on chance and that task results from others had also been useless. This information was intended to vary the extent to which subjects thought that they were responsible for the usefulness of their production. All subjects later learned that their task results were useless (i.e., negative consequences). Postexperimental ratings of the number 
task revealed that the task was seen as more enjoyable in the high than in the low-choice conditions, but only when subjects were led to feel responsible for the consequence. Thus these results clearly demonstrate that personal responsibility for negative consequences affects dissonance reduction processes. Similarly, Cooper (1971) has suggested that counterattitudinal behavior will produce dissonance if the actor feels personally responsible for the consequences of the behavior. According to Cooper (1971), personal responsibility is accepted if the person had free choice in performing the behavior and the person was able to foresee its negative consequences.

In some situations, however, a person would feel personally responsible for a consequence, even if there is no sufficient ground for that feeling from an objective point of view (see Wortman, 1975). The main purpose of the present study was to investigate whether the concept of personal resposibility suggested by Wicklund and Brehm (1976) could be extended to such a situation where an individual has to undergo a negative consequence caused by an agent beyond his control, i.e., by chance. Wicklund and Brehm's (1976) formulation leads to the following hypothesis with respect to a negative consequence caused by chance: If a person has a feeling of personal responsibility for a negative consequence even if he did not bring it about objectively, dissonance will be aroused. Hence the person will try to reduce the dissonance mainly by, in this case, underestimating the negative consequence itself. Wortman (1975) found that merely causing a chance outcome and having foreknowledge about the consequence induces a feeling of personal responsibility. Accordingly, the Wortman's (1975) procedure can provide a necessary basis for testing the hypothesis mentioned above.

A second purpose of the present study was to examine the possibility that ac- cepting or rejecting the personal responsibility may be used as a mode of dissonance reduction, although there are some methodological difficulties to test this idea strictly. These hypotheses are: (a) Even when conditions are not right for inducing responsibility, if the cognition reflecting a negative consequence is highly resistant to change, personal responsibility may be accepted retrospectively so that the negativity of the event could be ameliorated by means of dissonance reduction; (b) even when conditions are right for inducing responsibility, if the cognition reflecting a negative consequence is not highly resistant to change, personal responsibility may be rejected retrospectively to reduce or avoid possible dissonance. In order to help test the latter two hypotheses, the present experiment included the variable of " anticipated duration of the negative consequence" which was expected to vary the resistance-to-change of cognition reflecting the negative consequence.

An additional purpose of the present study was to examine the impact of cognitive dissonance on physiological variables. There is now fairly good evidence that the cognitive changes specified by dissonance theory are eventually manifested in physiological changes as well. For example, Zimbardo, Cohen, Weisenberg, Dworkin, and Firestone (1969) found that a subject who committed himself to receiving electric shock reduced his dissonance by lowering his felt level of pain. In addition, they demonstrated that GSR responses were lower for the highdissonance than the low-dissonance subjects. Glass and Mayhew (1969) replicated Zimbardo et al.'s (1969) findings in a similar situation. Furthermore, Brehm, Back, and Bogdonoff (1964) found that dissonance altered hunger level, and that it was reliably related to changes in the level of free fatty acids (FFA). In the present study, the participants' pulse rates were monitored throughout the experiment to examine whether the changes 
noted earlier in cognitions could be extended to the noncognitive components of pain. Measuring pulse rates was also expected to make the "cover story" of the experiment more plausible for the participants.

Theoretical expectations described thus far were investigated by means of a $2 \times$ $2 \times 2$ factorial design. In the present experiment, electric shock was utilized as a negative consequence. The first variable, causal agent, was whether a die was thrown by the experimenter (ExperimenterCaused condition) or by the participants themselves (Participant-Caused condition). The second variable, magnitude of negative consequence, was manipulated by the level of electric shock determined by casting a die (Large-Negative-Consequence versus Small-Negative-Consequence condition). The third variable, anticipated duration of negative consequence, was manipulated by telling the participants that a negative task would require either thirty minutes (Long-Duration condition) or only a few minutes (Short-Duration condition).

The hypotheses were as follows:

1. Participants in the Participant-Caused condition would accept more personal responsibility for the negative consequence, hence manifest greater dissonance reduction (e.g., underestimation of the negative consequence and self-justificatory attitude change) than participants in the Experimenter-Caused condition.

2. Within the Experimenter-Caused condition, participants in the Long-Duration condition would attribute more personal responsibility, hence show greater dissonance reduction than participants in the Short-Duration condition.

3. Within the Participant-Caused condition, participants in the Short-Duration condition would accept less personal responsibility, hence show less dissonance reduction than participants in the LongDuration condition.

\section{Method}

Participants. Eighty-three male undergraduates at the University of Tokyo participated individually in the experiment entitled " a study of the effects of tension state on human behavior." A total of three participants were not included in the analyses (one because he couldn't comprehend the instruction, one because he rejected to receive electric shock, one because of an equipment malfunction), leaving a final sample of eighty participants. All of them were paid 500 yen (approx. 2 dollars) for their participation at the end of the experiment.

Procedure. When the participant arrived for the experiment, the experimenter introduced himself and escorted him to the experimental room. He was seated at a table facing a small screen on which a "flow diagram of the experiment" was written. Then the experimenter gave him a general introduction:

The purpose of this study is to investigate how tension state affects human behavior. There are, of course, many studies which investigated its effects on the speed of learning, performance level, etc. But now, we are going to examine how conflict will be affected by the tension state. Conflict will be measured by the Stroop ColorWord Test which I'll explain later in detail. Please look at the sheet in front of you. It shows the flow diagram of the experiment. First, participants are divided into either a "high-tension group " or a "low-tension group". In order to assign participants randomly, we're going to use a die. This procedure will allow us to examine how the nature of the conflict will differ between the two groups. The level of the tension state will be manipulated by the strength of electric shocks administered to the participant's finger. That is, those who are assigned to the "low-tension group" will receive very 
weak shocks, whereas those who are assigned to the "high-tension group" will receive somewhat stronger shocks.

In order to minimize the induction of anxiety for receiving electric shocks and the "evaluation apprehension" (Rosenberg, 1965), the experimenter continued:

You don't need to concern about the electric shock you are going to receive, as it is not so strong as to do any harm to the tissue of your skin. And as I have already mentioned, the purpose of the present study is to investigate the effects of the tension state by comparing the "mean conflict scores" of the two groups. So I assure you that any data taken from this experiment will be used for statistical purposes only. Of course, we do not intend to measure your own personality or intelligence level via this task.

Then, the experimenter told the participant the rationale for attaching the electrodes to his finger:

Well, while you're engaging in the task, your pulse rate will be monitored by the apparatus you can see over there. As I need a few minutes to calibrate our recording instruments, will you let me attach the electrodes to your finger right now?

After adjusting the equipment, manipulations of the causal agent and the magnitude of negative consequence were introduced:

Let's decide which group you will be assigned by casting a die. If the die shows the spot(s) of odd numbers, you will be assigned to the "low-tension group "; in case of even numbers, you will be assigned to the "high-tension group".

For half of the participants, the die was thrown by the experimenter (Experimenter-Caused condition), while for the other half, it was thrown by the participant himself (Participant-Caused condition). According to the number of the spot(s), they were assigned " randomly" to either a "Large-Negative-Consequence (LNC) condition" or a "Small-Negative-Consequence (SNC) condition".

Then, the experimenter explained the experimental task. Simplified version of the Stroop Color-Word Test, developed by the present authors, consisted of four color nouns (" ao (blue)", "midori (green)", " aka (red)", "kiiro (yellow)") printed in incongruent combination of noun and color ink. Thus, the noun "aka (red)" was printed in blue or green ink, etc., and participants were required to pronounce the color of ink rather than the color noun. One session of the Stroop task consisted of twelve color-pronouncing trials, and the participant was presented with a sample card on which four sets of color words were printed. Participants were informed that they would receive an electric shock which lasted $2 \mathrm{~s}$ just before each session of the Stroop task. Furthermore, they were required to start to pronounce the color of ink as soon as they felt the electric shock. Then, the experimenter gave an instruction which constituted the manipulation of the anticipated duration of the negative consequence. In the Long-Duration (LD) condition, he said:

Well, you're required to perform thirty-two sessions. It'll take you about half an hour, although there are some individual differences.

In the Short-Duration (SD) condition, participants were informed that the task consisted of four sessions and it would take them only a few minutes.

The experimenter then told the participant the rationale for delivering a sample shock, the participant's estimation of which constituted a major dependent variable:

Let me give you a sample shock before the task. I think it's better for you to get an idea of what the shock will be like, and I'd also like to check how your pulse rate will change after receiving the shock.

Following this instruction, he taped the shock electrodes to the participant's finger 
and delivered a sample shock of either $.70 \mathrm{~mA}$ (LNG condition) or $.45 \mathrm{~mA}$ (SNC condition). The shock lasted $2.0 \mathrm{~s}$. Then, the participant was presented with a first questionnaire which asked his own estimation of the shock. Next, the participant was required to perform one session of the Stroop task "in order to acquaint him with the procedure required for the task." Following the exercise, the experimenter casually mentioned that he would like the participant to fill out a second questionnaire before beginning the actual pronunciation task. It was designed to assess the effectiveness of the responsibility manipulation, perceptions of the Stroop task, perceptions of the experimenter, etc., which were expected to be related to dissonance reduction. After completing the second questionnaire, the experiment was over. The participant was thoroughly debriefed and sworn to secrecy. The debriefing revealed that no participants entertained any suspicions about the experiment and that the "experimental realism" (Carlsmith, Ellsworth, \& Aronson, 1976) was reliably high.

Dependent measures. The first questionnaire contained seven questions which were designed to assess the negativeness of the electric shock. For example, Item 1 asked the participants, "How painful was the shock?" Item 2 asked them, "How uncomfortable was the shock?" Item 6 asked them, "How much has your heart rate got faster after receiving the shock?" All responses were made on 7-point scales labeled from 1 ("Not at all ") to 7 (" Extremely"). On each item, the greater the scale value, the greater the participants assessed the negativeness of the shock.

The second questionnaire contained several filler items as well as eight questions that served as manipulation checks or dependent variables. The responsibility manipulation check ("How responsible do you feel you personally are for receiving the shock of the present level?") ranged from 1 ("Not at all responsible") to 7
("Extremely responsible"). The participants were also asked to indicate how they perceived the experimenter on 7-point semantic differential-type scales anchored by the following bi-polar adjective pairs: Intelligent-unintelligent, rude-polite, warm-cold, trustworthy-untrustworthy, favorable-unfavorable. The other questions asked them to assess the perception of the Stroop task ("How enjoyable is the task you are going to perform?"), the perception of the present experiment itself ("How much contribution do you think this experiment can make to the progress of psychology?"), etc. Responses to these questions were also made on 7point scales.

\section{Results}

Responsibility measure. A $2 \times 2 \times 2$ ANOVA was performed on the responsibility measure. Contrary to our expectation, the analysis didn't yield a significant main effect for the Causal Agent factor, $F(1,72)<1$, That is, participants didn't report greater feelings of responsibility in the Participant-Gaused condition $(M=$ 2.85) than in the Experimenter-Caused condition $(M=3.18)$. It seems too early, however, to conclude that the responsibility manipulation was not effective. First, this result might be due to the fact that participants were not completely sure for what they were asked to assess the degree of personal responsibility. Actually, some participants asked the experimenter to clarify the precise meaning of the question, and some others clearly miscomprehended it as responsibility for " accepting to participate in the experiment". A second reason, which is related to the first one, may be that the term "responsibility" and the corresponding Japanese term "sekinin" (" responsibility" is commonly translated as such) have somewhat different connotations. The impression of the Japanese term "sekinin" might be too serious in such 
a context of the present experiment. Third, it may simply have been quite difficult for any participant to answer about personal responsibility for such a pure chance event as a result of casting a die. Taking these into consideration, it was determined to conduct further analyses on the dependent variables, although the responsibility manipulation was seemingly unsuccessful.

Intensity of the electric shock. The actual intensity of the electric shock administered to each participant was checked by the experimenter. It was revealed that the intensity did not differ systematically as a function of the Causal Agent $(F<1)$ or the Anticipated Duration of Negative Consequence factor $(F<1)$.

Perceptions of the electric shock. $2 \times 2 \times 2$ ANOVAs were performed separately on the seven measures of the perceived negativeness of the electric shock. All analyses yielded significant main effects for the Magnitude of Negative Consequence factor, $F_{\mathrm{S}}(1,72) \geq 6.68, p<.01$, which is not too surprising. Two out of the seven measures yielded significant main effects for the Causal Agent factor. As expected, participants in the Participant-Caused condition perceived the shock less painful than participants in the ExperimenterCaused condition ( $M=2.00$ vs. 2.40 , respectively). This result was characterized by, though marginally, a significant main effect for the Causal Agent factor, $F(1,72)$ $=2.99, p<.09$. The three-way interaction was also significant, $F(1,72)=6.68, p<.05$, which was mainly due to the high value in the Experimenter-Caused/SNC/SD cell $(M=2.70)$. In addition, as can be seen in Table 1, participants in the Experimenter-Caused condition estimated that their heart rates had got more faster after receiving the electric shock than participants in the Participant-Caused condition ( $M=2.15$ vs. 1.60 , respectively). ANOVA on this measure yielded a significant main effect for the Causal Agent factor, $F(1,72)$ $=7.41, p<.01$. These results support the
TABLE 1

Effects of causal agent, magnitude of negative consequence, anticipated duration of negative consequence on the estimated heart rate change

\begin{tabular}{c|c|c}
\hline \multirow{2}{*}{ Causal agent } & \multicolumn{2}{|c}{$\begin{array}{c}\text { Magnitude of negative } \\
\text { consequence }\end{array}$} \\
\cline { 2 - 3 } & Small & Large \\
\hline Experimenter-Caused & & \\
Short duration & 2.1 & 2.0 \\
Long duration & 1.3 & 3.2 \\
Participant-Caused & & \\
Short duration & 1.5 & 1.7 \\
Long duration & 1.2 & 2.0
\end{tabular}

Note. The higher the score, the greater the estimated increase in heart rate. For all cells, $n=10$.

first hypothesis that individuals who caused a chance negative consequence reduce their dissonance by underestimating the very negativeness of the consequence. ANOVA on the estimated heart rate change measure also yielded a significant effect for the Anticipated Duration of Negative Consequence $\times$ Magnitude of Negative Consequence interaction, $F(1,72)$ $=10.35, p<.01$. This is due to the fact that the impact of the latter variable was more pronounced in the LD condition than in the SD condition.

The second and third hypotheses, which concern the mode of dissonance reduction, were examined by comparing the means of the SD and the LD conditions in the Experimenter- or the Participant-Caused condition. On the above two measures, it was revealed that the differences of means between the LD and the SD conditions were negligible for the both measures: Within the Experimenter-Caused condition, participants in the LD condition did not feel the shock less painful $(M=2.30)$ and did not estimate less increase in heart rate $(M=2.25)$ than participants in the SD condition $(M \mathrm{~s}=2.50$ and 2.05, respectively), $F_{S}<1$, for the both 
measures; within the Participant-Caused condition, the differences of means between the SD and the LD conditions were also insignificant. This pattern of results was almost identical among the other five dependent measures. So it can be concluded from these analyses that the two hypotheses were not supported by the present data.

Perception of the experimenter. $2 \times 2 \times 2$ ANOVAs were separately performed on the data from the five semantic differentialtype scales. As expected, participants in the Participant-Caused condition perceived the experimenter significantly more " intelligent" than participants in the Experimenter-Caused condition $(M=5.45$ vs. 4.80 , respectively), $F(1,72)=7.28, p<$ .01 (see Fig. 1). In addition, participants in the Participant-Caused condition perceived him significantly more "favorable" than participants in the ExperimenterCaused condition ( $M=4.68$ vs. 4.18 , respectively), $F(1,72)=4.48, p<.05$. These results seem to show that participants in the Participant-Caused condition manifested greater dissonance reduction (i.e., self-justificatory attitude change) than participants in the Experimenter-Caused condition.

The other questionnaire measures. There

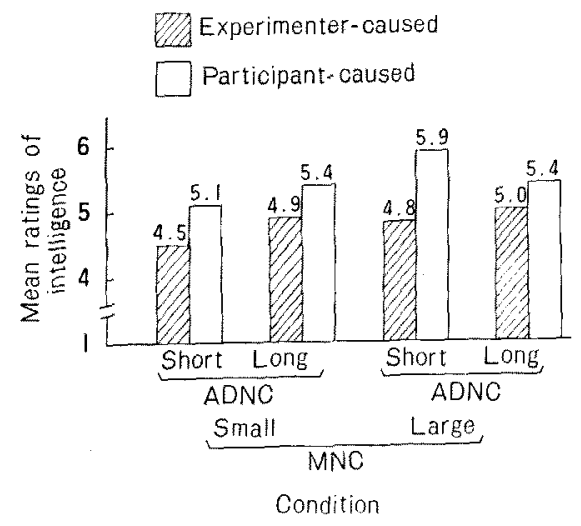

Frg. 1. Effects of causal agent, magnitude of negative consequence (MNC), anticipated duration of negative consequence (ADNC) on the ratings of the experimenter's intelligence.
TABLE 2

Effects of causal agent, magnitude of negative consequence, anticipated duration of negative consequence on the actual pulse rate change

\begin{tabular}{c|c|c}
\hline \multirow{2}{*}{ Causal agent } & \multicolumn{2}{|c}{$\begin{array}{c}\text { Magnitude of negative } \\
\text { consequence }\end{array}$} \\
\cline { 2 - 2 } Experimenter-Caused & & Large \\
Short duration & 10.86 & 3.25 \\
Long duration & 8.23 & 7.66 \\
Participant-Caused & & \\
Short duration & 3.58 & $10.54 \dagger$ \\
Long duration & 3.51 & 6.48
\end{tabular}

Note. Positive numbers indicate the increase in pulse rate (bpm).

$\dagger$ Two samples in this cell were excluded from the analysis because of the misoperation of the recording instrument. The resultant $n$ was 8 . For the other cells, $n=10$.

were no significant effects of the independent variables upon the measures assessing the participants' perceptions of the Stroop task and the " present experiment" itself, etc. Accordingly, detailed statistical results are not reported here.

Physiological measure. The actual pulse rate data were reduced to make " change scores" by the following procedure: First, a base line of the participant's pulse rate was scored over 10 beats immediately preceding the Causal Agent manipulation into the number of beats per minute. Then, a postshock pulse rate was also scored over 10 beats immediately following the onset of the electric shock. Change scores, which were utilized for the statistical analysis, were calculated by simply subtracting the base line scores from the postshock scores. The mean change scores are presented in Table 2. Participants in the Participant-Caused condition showed smaller increase than participants in the Experimenter-Caused condition ( $M=5.79$ vs. 7.50 , respectively). Although the direction of this effect was consistent with that of the estimated heart 
Table 3

Summary of the analysis of variance on the estimated heart rate change and actual pulse rate change measures

\begin{tabular}{|c|c|c|c|c|c|c|}
\hline \multirow{2}{*}{ Source } & \multicolumn{3}{|c|}{ Estimated heart rate change } & \multicolumn{3}{|c|}{ Actual pulse rate changet } \\
\hline & $d f$ & MS & $F$ & $d f$ & MS & $F$ \\
\hline Causal agent (A) & 1 & 6.05 & $7.41^{* *}$ & 1 & 55.97 & $<1$ \\
\hline $\begin{array}{l}\text { Anticipated duration of } \\
\text { negative consequence (B) }\end{array}$ & 1 & .20 & $<1$ & 1 & 2.59 & $<1$ \\
\hline $\begin{array}{l}\text { Magnitude of negative } \\
\text { consequence (C) }\end{array}$ & 1 & 9.80 & $12.00^{* *}$ & 1 & .89 & $<1$ \\
\hline $\mathrm{A} \times \mathrm{B}$ & 1 & .20 & $<1$ & 1 & 37.74 & $<1$ \\
\hline $\mathrm{A} \times \mathrm{C}$ & 1 & .80 & $<1$ & 1 & 383.16 & 3.77 \\
\hline $\mathrm{B} \times \mathrm{C}$ & 1 & 8.45 & $10.35 * *$ & 1 & 13.88 & $<1$ \\
\hline $\mathrm{A} \times \mathrm{B} \times \mathrm{C}$ & 1 & 2.45 & 3.00 & 1 & 147.49 & 1.45 \\
\hline Error & 72 & .82 & & 70 & 91.72 & \\
\hline
\end{tabular}

+ Data of two samples were excluded from the analysis because of the misoperation of the recording instrument.

$* * p<.01$

rate change, a $2 \times 2 \times 2$ ANOVA on this measure did not reveal a significant main effect for the Causal Agent factor, $F(1,70)$ $<1$. None of the other main or interaction effects were also significant (see Table 3).

\section{Discussion and Conclusion}

Personal responsibility and dissonance reduction. The first hypothesis was supported by the present results. Participants in the Participant-Caused condition seem to have reduced their dissonance by underestimating the negativeness of the event and/or by evaluating the experimenter more positively. However, as mentioned in the earlier section, the feelings of personal responsibility were not affected by the causal agent manipulation. This fact may lead to the conclusion that the obtained results were not due to the process suggested by Wicklund and Brehm (1976). For example, assuming that an individual is motivated to determine his fate by his own deed, the behavior of the experimenter, i.e., having allowed the participants to cast a die, might have been rewarding to the participants in the Partici-
pant-Caused condition. Thus, it is not surprising that participants in the Participant-Caused condition evaluated the experimenter more positively than did participants in the Experimenter-Caused condition (Lott \& Lott, 1974). Although this explanation by a reinforcement model seems plausible as far as the participants' perception of the experimenter is concerned, it is almost impossible to extend it to cover the obtained differences in the perceptions of the electric shock. Rather, these findings, taken in conjunction with the results of Wortman (1975) and Zimbardo et al. (1969) studies, seem to suggest that dissonance reduction did occur but the measuring instruments were not sophisticated enough to detect the difference in the felt level of personal responsibility. What is most important should be, then, to construct a reliable instrument for measuring personal responsibility, particularly suitable for Japanese participants. Further, a more sophisticated experimental design should be utilized, because measuring personal responsibility itself seems to lessen the plausibility of the experimental situation. For example, future research can employ the Solomon- 
type experimental design where the participants' felt responsibility is " estimated " from the actually measured responsibility of other "participants" who do not proceed to the measurement of dependent variable(s) (Solomon, 1949; Lana, 1969). Much research should be done, using such a strict procedure, to identify conditions which affect attribution of personal responsibility for consequences of one's behavior (Eagly \& Himmelfarb, 1978).

There was no evidence supportive of the second and third hypotheses. Although the check of the manipulation of the anticipated duration of negative consequence variable was not included in the present experiment, it is probable that this manipulation was not completely effective. Since most participants seem to have expected that the experiment was to last for more than an hour, participants in the Long-Duration condition might take the instruction concerning the time required for the experiment as a matter of course. ${ }^{2}$ Thus, the resistance-to-change of cognition of the negative consequence was relatively low even for the participants in the Long-Duration condition. Responsibility acceptance, one mode of dissonance reduction, might be employed if a negative event should be surely and unchangeably endurable. From an ethical point of view, it seems very difficult, if not impossible, to create such a situation in a laboratory.

Physiological response. Some researchers found that the impact of dissonance is strong enough to affect a noncognitive (physiological) response class (Brehm et al., 1964; Zimbardo et al., 1969). Detweiler and Zanna (1976) found that an external stimulus results in a real physio-

\footnotetext{
2 In the University of Tokyo, students enrolled in an introductory psychology course are required at the beginning of the term to fill out a form where they have to check the "hours" in a week when they can participate in psychological experiments. In the present experiment, participants were drawn from this pool.
}

logical change, which in turn results in attitude. In the present study, however, it was not the case. Participants in the Participant-Caused condition did underestimate the negativeness of the electric shock, but it was not accompanied by the actual pulse rate change. However, it cannot be determined from the present study whether this inconsistency is attributable to the difference in manipulation employed or the difference in response mode. That is, the reason for this inconsistency may be that the responsibility manipulation employed in the present experiment was not so strong as to affect the physiological variable or that the pulse rate measure was less sensitive than the GSR measure to detect changes in arousal level after receiving the electric shock.

To summarize, the conclusion that seems warranted is that the present study identified conditions which affect dissonance reduction processes after a person has faced a negative event caused under no personal control. Those who caused a chance negative event themselves manifested greater dissonance reduction than those whom the other person caused it, although the attribution of personal responsibility for the negative event did not differ between the two groups. It should be noted, of course, that much research needs to be done before precise predictions can be made concerning the relationship between personal responsibility and dissonance reduction.

\section{REFERENCES}

Aronson, E. 1968 Dissonance theory: Progress and problems. In R. P. Abelson, E. Aronson, W.J. McGuire, T. M. Newcomb, M.J. Rosenberg, \& P. H. Tannenbaum (Eds.), Theories of cognitive consistency: $A$ sourcebook. Chicago: Rand-McNally, Pp. 5-27.

Brehm, J. W., \& Cohen, A. R. 1962 Explorations in cognitive dissonance. New York: Wiley.

BrehM, M. L., BACK, K. W., \& BocdonofF, M. D. 1964 A physiological effect of cognitive dis- 
sonance under stress and deprivation. Journal of Abnormal and Social Psychology, 69, 303-310.

Carlsmith, J. M., Ellsworth, P. C., \& Aronson, E. 1976 Methods of research in social psychology. California: Addison-Wesley.

Cooper, J. 1971 Personal responsibility and dissonance: The role of foreseen consequences. Journal of Personality and Social Psychology, 18, 354-363.

Detweiler, R. A., \& Zanna, M. P. 1976 Physiological mediation of attitudinal responses. Journal of Personality and Social Psychology, 33, 107-116.

EAGLY, A.H., \& Himmelfarb, S. 1978 Attitudes and opinions. Annual Review of Psychology, 29, 517-554.

Festinger, L. 1957 A theory of cognitive dissonance. Evanston, Illinois: Row, Peterson.

Glass, D. C., \& Mayhew, P. 1969 The effects of cognitive processes on skin conductance reactivity to an aversive film. Psychonomic Science, 16, 72-74.

Greenwald, A. G., \& Ronis, D. L. 1978 Twenty years of cognitive dissonance: Case study of the evolution of a theory. Psychological Review, 85, 53-57.

LANA, R. E. 1969 Pretest sensitization. In R. Rosenthal \& R. L. Rosnow (Eds.), Artifact in behavioral research. New York: Academic Press, Pp. 121-140.

LotT, A.J., \& LotT, B.E. 1974 The role of reward in the formation of positive interpersonal attitudes. In T. L. Huston (Ed.), Foundations of interpersonal attraction. New York: Academic Press, Pp. 171-189.

Ned, E., Helmreich, R., \& Aronson, E, 1969 Opinion change in the advocate as a function of the persuasibility of his audience: A clarification of the meaning of dissonance. Journal of Personality and Social Psychology, 12, 117-124.

Rosenberg, M. J. 1965 When dissonance fails: On eliminating evaluation apprehension from attitude measurement. Journal of Personality and Social Psychology, 1, 28-42.

Sogin, S. R., \& Pazlax, M. S. 1976 Bad decisions, responsibility, and attitude change: Effects of volition, foreseeability, and locus of causality of negative consequence. Journal of Personality and Social Psychology, 33, 300-306.

Solomon, R. L. 1949 An extension of control group design. Psychological Bulletin, 46, 137-150.

Wigklund, R. A., \& Brehm, J.W. 1976 Perspectives on cognitive dissonance. Hillsdale, New Jersey: Lawrence Erlbaum Associates.

WortMAN, C.B. 1975 Some determinants of perceived control. Journal of Personality and Social Psychology, 31, 282-294.

Zimbardo, P. G., Cohen, A., Weisenberg, M., DWORKIN, L., \& Firestone, I. 1969 The control of experimental pain. In P. G. Zimbardo (Ed.), The cognitive control of motivation. Atlanta: Scott, Foresman and Company, Pp. 100-125.

(Received August 13, 1979) 